\title{
Desafios técnicos e institucionais na aplicação de instrumentos inovadores de planejamento e gestão urbanos: o caso de Hortolândia - São Paulo
}

\author{
Institutional and technical challenges on the implementation of \\ innovative urban planning and management instruments: the \\ case of Hortolândia - São Paulo
}

\author{
Desafios técnicos y institucionales en la aplicación de \\ instrumentos de planificación y gestión urbana innovadora: el \\ caso de Hortolândia - São Paulo
}

\author{
Maurício Polidoro \\ mauricio.polidoro@sertao.ifrs.edu.br \\ Instituto Federal de Educação, Ciência e Tecnologia do Rio Grande do Sul
}

\begin{abstract}
Resumo: O artigo versa sobre o processo de construção da revisão do Plano Diretor do município de Hortolândia - região metropolitana de Campinas. Eminentemente industrial, o município emancipou-se de sua sede, Sumaré, na década de 1990 e, apesar da reduzida área territorial, tem apresentado crescimento demográfico e econômico vertiginoso. A despeito disso, as políticas urbanas não têm acompanhado a demanda de solução dos problemas. No intento de atender as demandas sociais, ambientais e urbanísticas, a revisão do Plano Diretor trouxe alguns instrumentos inovadores para o planejamento e gestão de Hortolândia. Os desafios técnicos e institucionais de aplicação destes instrumentos serão discutidos.
\end{abstract}

Palavras-chave: Plano Diretor, Instrumentos urbanísticos, Planejamento Urbano, Hortolândia, São Paulo.

Abstract: The paper is about the revising process of the Hortolandia municipality Master Plan, located in the metropolitan region of Campinas. Eminently industrial, the municipality has emancipated itself from its headquarters, Sumaré, in the 1990s and, despite the reduced land area, has shown staggering demographic and economic growth. Nevertheless, urban policies has not matched the demand for solving problems. In attempt to meet social, environmental and urban planning demands, the revision of the Master Plan has brought some innovative tools for planning and management of Hortolândia. The technical and institutional challenges of applying those instruments will be discussed.

Keywords: Master Plan, Urban instruments, Urban Planning, Hortolandia, Sao Paulo.

Resumen: El artículo trata sobre el proceso de construcción de revisión del Plan Director de la Ciudad de Hortolândia - la región metropolitana de Campinas. Eminentemente industrial, el municipio se ha emancipado de su sede, Sumaré, en la década de 1990 y, a pesar de la reducida superficie de tierra, ha mostrado un crecimiento impresionante 
económico y demográfico. Sin embargo, las políticas urbanas no han coincidido con la demanda de la solución de problemas. En un intento por satisfacer las demandas sociales, la planificación ambiental y urbana, la revisión del Plan Director ha llevado a algunas de las herramientas innovadoras para la planificación y gestión de Horton. Los desafíos técnicos e institucionales de la aplicación de estos instrumentos serán discutidos.

Palabras clave: Plan Maestro, Instrumentos urbanisticos, Planificación urbana, Hortolandia, Sao Paulo.

\section{INTRODUÇÃO}

O aparato legal disponibilizado pelo Estatuto da Cidade no que concernem instrumentos urbanísticos para o planejamento e gestão das cidades brasileiras representa, de fato, um avanço na temática. Entretanto, diversos desafios surgem na execução desses instrumentos na escala municipal. Os desafios vão desde a ação integrada entre os grupos hegemônicos produtores do espaço urbano na execução de projetos particulares, como a dificuldade técnica no poder público para compreender e aplicar os instrumentos existentes. Além disso, as peculiaridades locais exigem que os gestores públicos passem para além do disponível na legislação federal, desenvolvendo mecanismos de planejamento e gestão urbanos inovadores, capazes de solucionar ou, ao menos, enfrentar dilemas marcantes em algumas cidades.

Neste contexto, se insere o município de Hortolândia, que, segundo o IBGE, no ano de 2010, possuía uma população de 192.225 mil habitantes. ${ }^{1}$ Inserida na região metropolitana de Campinas (RMC), o montante populacional neste complexo urbano soma 2.832.297 milhões de habitantes, distribuídos em dezenove municípios paulistas. Hortolândia, que se emancipou na década de 1990 de sua antiga sede, Sumaré, é caracterizada principalmente por acolher indústrias multinacionais de alta tecnologia.

Constituindo-se como uma das municipalidades mais prósperas para o desenvolvimento econômico devido à sua localização estratégica e a consolidada indústria de alta tecnologia, Hortolândia revela, no seu espaço intraurbano, mazelas sociais e ambientais, marcadas pela poluição de suas nascentes, inexistência de áreas verdes e precariedade habitacional. Com um intenso movimento pendular para Campinas, Hortolândia ganha diariamente 1.831 pessoas destinadas a trabalhar nas empresas de alta tecnologia e perde cerca de $13 \%$ da sua população, de baixa qualificação, para trabalhar nos municípios da RMC (IBGE, 2000).

Cidade-dormitório de Campinas, com parque industrial de empresas de impactos ambientais notáveis, a sua pequena área territorial de $62 \mathrm{~km}^{2}$ é quatro vezes menor que algum dos seus vizinhos como Monte Mor e Paulínia. Esta reduzida área traz implicações e dilemas devido à ocupação desordenada das indústrias, comércios e residências que convivem mutuamente e conflituosamente.

1 Segundo previsão do Plano Diretor (p. 70), até 2030 o município deve atingir 400 mil habitantes. 
O artigo propõe, assim, analisar criticamente o processo de construção da revisão Plano Diretor de Hortolândia, onde alguns instrumentos inovadores foram propostos para conter a expansão urbana caótica, considerando as peculiaridades locais. Dentre os instrumentais, a lei de zoneamento, inovadora, propôs a interface entre os aspectos ambientais e os urbanísticos para traçar um novo zoneamento, com vistas a suprimir os extensos vazios urbanos existentes e ceder espaço a uma cidade mais compacta e sustentável.

Outra proposta inovadora é a criação de corredores de proteção ambiental no entorno dos anéis viários e ferroviários que permeiam o município e que trazem comprovadamente dilemas para a população local. Por fim, versaremos sobre os desafios técnicos e institucionais na aplicação das propostas executadas no Plano Diretor que traz ainda ferramentas para mitigação de impactos de vizinhança na pós-ocupação.

\section{A PRODUÇÃO E REPRODUÇÃO DO ESPAÇO URBANO DESIGUAL DE HORTOLÂNDIA - SP}

São notórias, nas últimas décadas, as transformações que as cidades médias, os aglomerados urbanos e as metrópoles brasileiras têm sofrido como mostra dados recentes do IBGE (2000; 2010). De acordo com IPEA (2008), os dois primeiros grupos possuem taxas de crescimento populacional e participação na economia nacional em crescimento, enquanto as metrópoles e as cidades pequenas encolheram ou permaneceram estancadas.

As cidades médias, que, no paradigma do desenvolvimento hierárquico urbano desejável, é símbolo do desenvolvimento como observa Damiani (2008), passa a figurar como um dos palcos principais de um novo arranjo da rede urbana nacional. Diante dos ordenamentos de uma economia global caracterizada nas escalas regionais e intraurbana pela competição municipal e guerra fiscal, as cidades médias atraem, sobretudo devido às facilidades proporcionadas às corporações, indústrias e empreendimentos que (re)modelam os espaços urbanos acirrando suas desigualdades, em multiescalas.

Enquanto Santos (1996) apontou que a partir de 1970 a urbanização deixou de ser da sociedade, materializando-se no território, Lencioni (2011) indica que o momento atual é de metropolização do espaço, ou seja, o processo de metropolização é a expressão de uma nova época na qual a metrópole se coloca ao mesmo tempo enquanto condição para a reprodução do capital e também um meio para a sua reprodução constituindo-se, concomitantemente, como um produto do capital. Ressalta-se, contudo, que este processo - se observamos, por exemplo, nosso recorte de estudo - não se refere apenas e somente ao município polo da metrópole, englobando todo o complexo metropolitano, ou seja, as cidades médias do entorno que dão suporte a esta condição metropolitana.

Este processo marcado a partir da década de 1970 no estado de São Paulo pela interiorização da indústria consolidou a capital paulista enquanto centro financeiro decisório e o interior, intensamente a partir de 1980, como lócus da produção industrial. Singer (1973) aponta que a concentração do capital e o processo de metropolização são 
reforçados mutuamente pela concentração de atividades em estabelecimentos e firmas cada vez maiores e a concentração de atividades em determinadas áreas geográficas.

Na escala espacial local, entendida a partir de Corrêa (2011) onde as práticas humanas ocorrem em âmbitos espaciais que são ora limitada, ora ampla, é a principal arena das relações entre os diferentes atores: globais e locais. Estas relações são proporcionadas pela crescente ampliação das relações econômicas em escala internacional, mediada por sistemas técnicos e por práticas políticas e econômicas que exigem ampliação das escalas para melhor compreensão das ações destes agentes (SPÓSITO, 2011).

A lógica compreendida e analisada por estes e outros diferentes autores é (re)produzida no município de Hortolândia na ação dos diferentes grupos econômicos atuantes neste espaço, articulados com o poder público local que se relacionam, mutuamente, com o poder regional e internacional. A figura 1 indica a localização do município de Hortolândia e sua ex-Sede, Sumaré, no contexto da região Metropolitana de Campinas.

Figura 1 - Contexto de Hortolândia no estado de São Paulo e região Metropolitana de Campinas

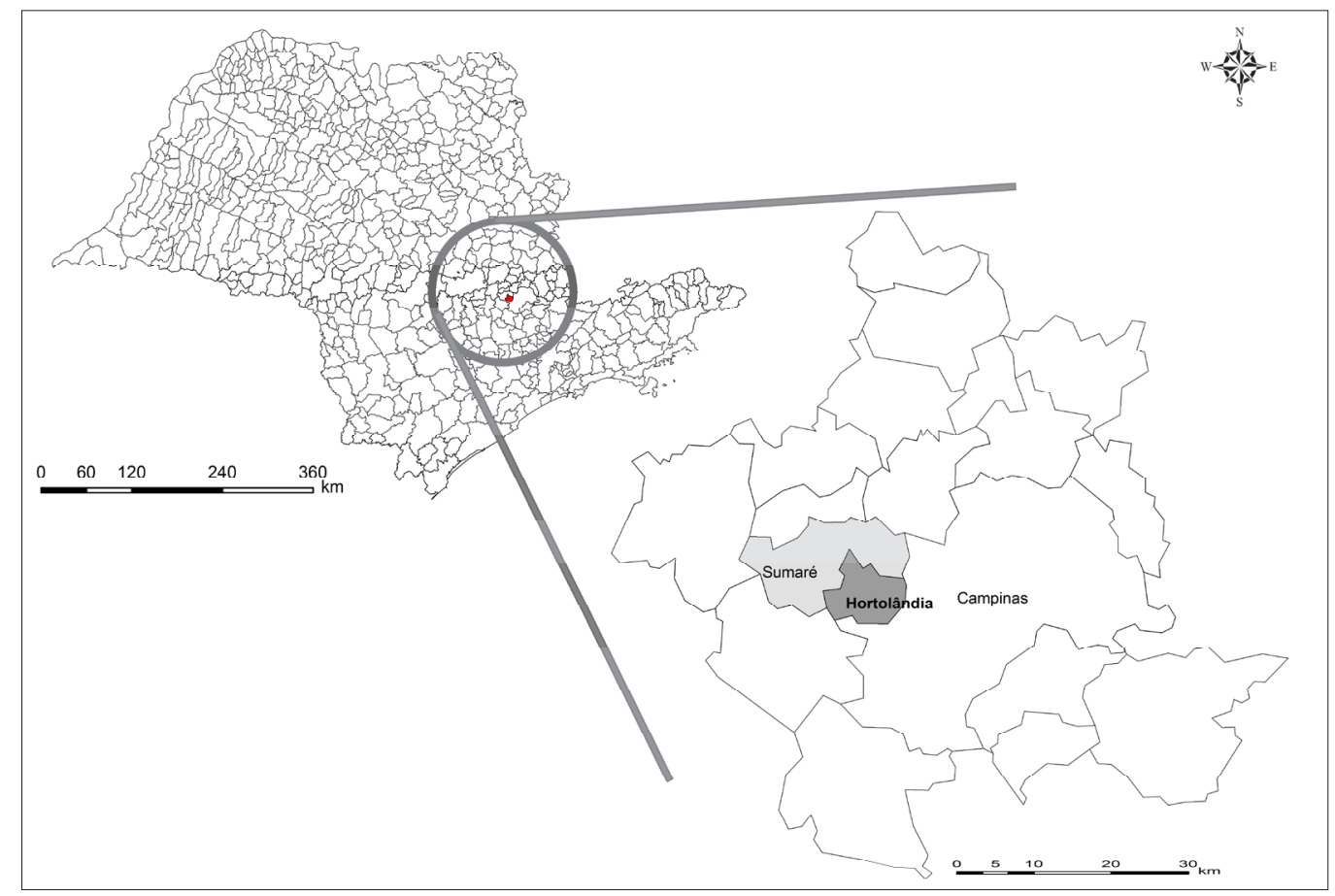

Organização: Autor (2012)

Esta multiescalaridade de relações teve sua gênese em Hortolândia a partir do processo de interiorização da indústria paulista. A facilidade de instalação de grandes grupos na região de Campinas proporcionado pela flexibilização da legislação, redução e/ou isenção de impostos e doação de terrenos impulsionou o então distrito de Sumaré enquanto lócus de empresas de alta tecnologia como IBM, EMS, Wickbold, Dell, GKN, Mabe, Dow Corning, Magnetti Marelli, CAF, Amsted Maxion, Lanmar, Gonvarri e outras. O crescimento demográfico e econômico, superior da sua então sede, levou a emancipação em 19 de maio de 1991. 


\section{HORTOLÂNDIA: DE SESMARIAS A TERRA DO FUTURO}

Presente da Coroa Portuguesa a senhores do engenho do interior paulista, Hortolândia tem suas raízes ligadas a Campinas, polo da atual região metropolitana. A consolidação da produção da cana-de-açúcar, do café, algodão e agropecuária tornou a região, ainda no século XIX, enquanto foco de pujança econômica.

Com o processo de interiorização da indústria paulista, a partir da década de 1970, a cidade de Campinas passa então a concentrar as principais indústrias de tecnologia do estado de São Paulo, apesar do sistema decisório permanecer da capital. O encarecimento das terras em Campinas e sua consolidação enquanto local de produção técnica e científica fez com que as indústrias de impacto significativo fossem se instalando nos municípios vizinhos, via guerra fiscal. Como seus limítrofes, Hortolândia flexibilizou sua legislação e doou terras a grandes grupos, o que culminou na circulação de cifras extraordinárias na economia local.

A instalação das indústrias não trouxe, entretanto, o acesso a terra e habitação para a população que, intensamente, foi se instalando na região. $\mathrm{O}$ alto custo da terra e dos serviços em Campinas e a sua proximidade de Hortolândia fez com que esta sediasse a população com menor poder aquisitivo. Por outro lado, a população mais abastada, desinteressada de morar em Campinas, foi para Vinhedo, sede de diversos condomínios fechados de alto padrão. O fenômeno de movimentos pendulares em Hortolândia e Vinhedo é parecido, contudo em direções divergentes.

De acordo com estudo de Sobreira e Cunha (2007), diariamente, Hortolândia perde $16,81 \%$ da sua população em movimentos pendulares. Na pesquisa, computou-se que 30.487 habitantes vão trabalhar ou estudar em municípios da região metropolitana de Campinas e outros 1.663 vão para a cidade de São Paulo. A renda média dessa população pendular, de acordo com o estudo de Pereira (2007), é de R\$557,30, considerando o Censo de 2000 do IBGE.

Pereira (2007) indica que o movimento pendular de Campinas para Hortolândia é, por outro lado, bem menos intenso e provocado pela classe média. Na época do censo, o rendimento dessa população era de $\mathrm{R} \$ 1.616,40$ e totalizava apenas 1.831 pessoas que vão trabalhar nos polos de alta tecnologia de Hortolândia. Este movimento tem impacto direto no município, onde as principais vias com congestionamento são as que ligam grandes empresas a Campinas.

Esse movimento pendular na região metropolitana de Campinas ocorre de formas diferentes entre os municípios. Enquanto Hortolândia reúne indicadores socioeconômicos baixos, pouca infraestrutura e é caracterizada por um processo de ocupação urbana heterogênea, combinada com a atração de migrantes de baixa renda iludidos pela implantação de grandes empresas (PEREIRA \& HERRERO, 2009), o município próximo, Vinhedo, é o oposto: possui uma ocupação mais recente, com condomínios de alto padrão e ótimos indicadores socioeconômicos.

Assim, Vinhedo é local de moradia de parcela da população que escolhe não viver em Campinas devido a problemas urbanos como congestionamentos, poluição, 
insegurança e preferem deslocar-se diariamente em troca de residências de alto padrão, dotadas de infraestrutura e qualidade ambiental. Já Hortolândia carrega o estigma de uma população de classe baixa, significativos impactos ambientais e a disseminação da ilusão (como se pode observar na figura 2) de que grandes corporações proporcionam empregos. De fato proporcionam, porém não para a população do município sede.

Figura 2 - Marketing utilizado pela prefeitura: Hortolândia, a cidade próspera que mais cresce no Brasil

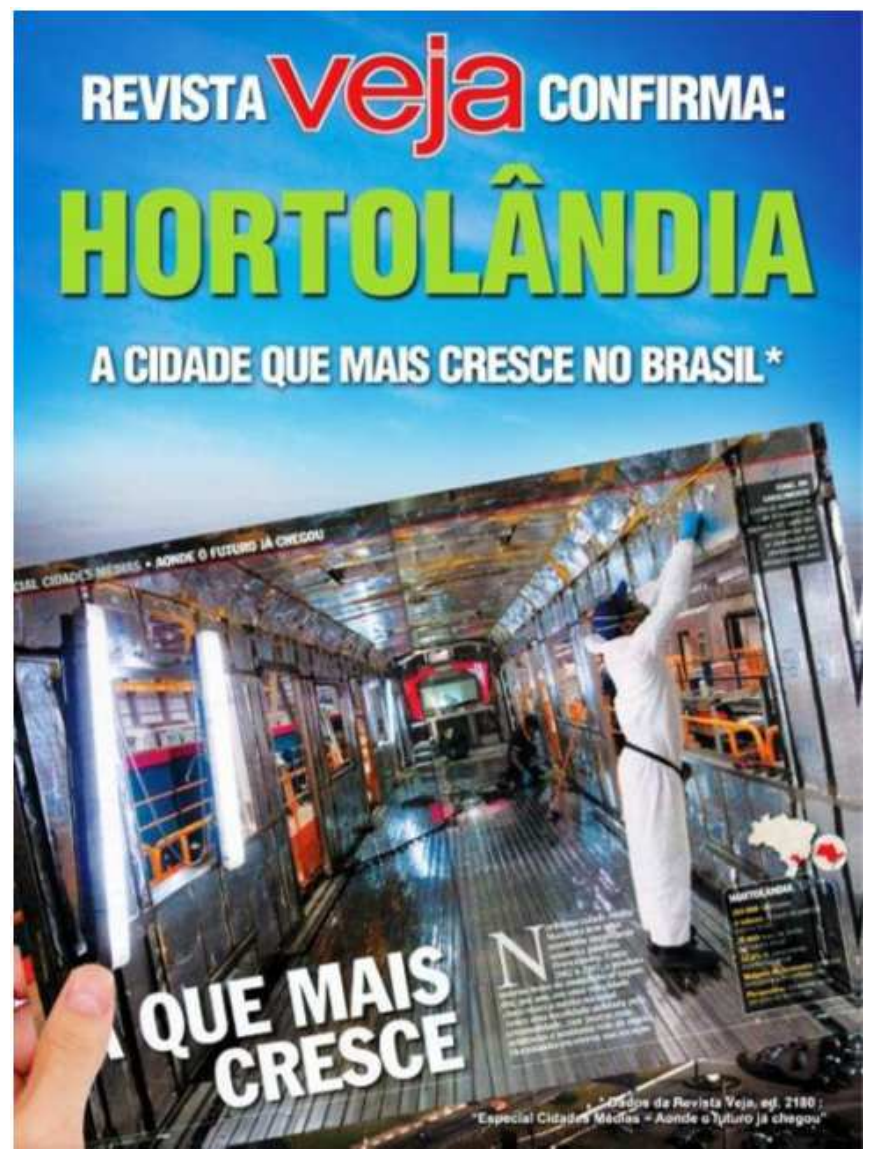

Fonte: Revista Veja - agosto de 2010.

\section{PROPOSTAS INOVADORAS DO NOVO PLANO DIRETOR}

Dois principais problemas balizadores foram enfrentados na revisão do Plano Diretor de Hortolândia. De um lado, a existência de grandes grupos econômicos, ao mesmo tempo impactantes e essenciais na geração do PIB municipal. De outro lado, a existência de um zoneamento rígido, diversos vazios urbanos e a necessidade de proporcionar acesso à terra para os moradores excluídos da cidade e, em concomitância, incentivar novos empreendimentos não poluentes numa ínfima área territorial de $62,503 \mathrm{~km}^{2}$ (IBGE, 2012) onde $43 \%$ são vazios urbanos. A figura 3 demonstra as principais características do espaço urbano de Hortolândia. 
Figura 3 - Características do espaço urbano de Hortolândia

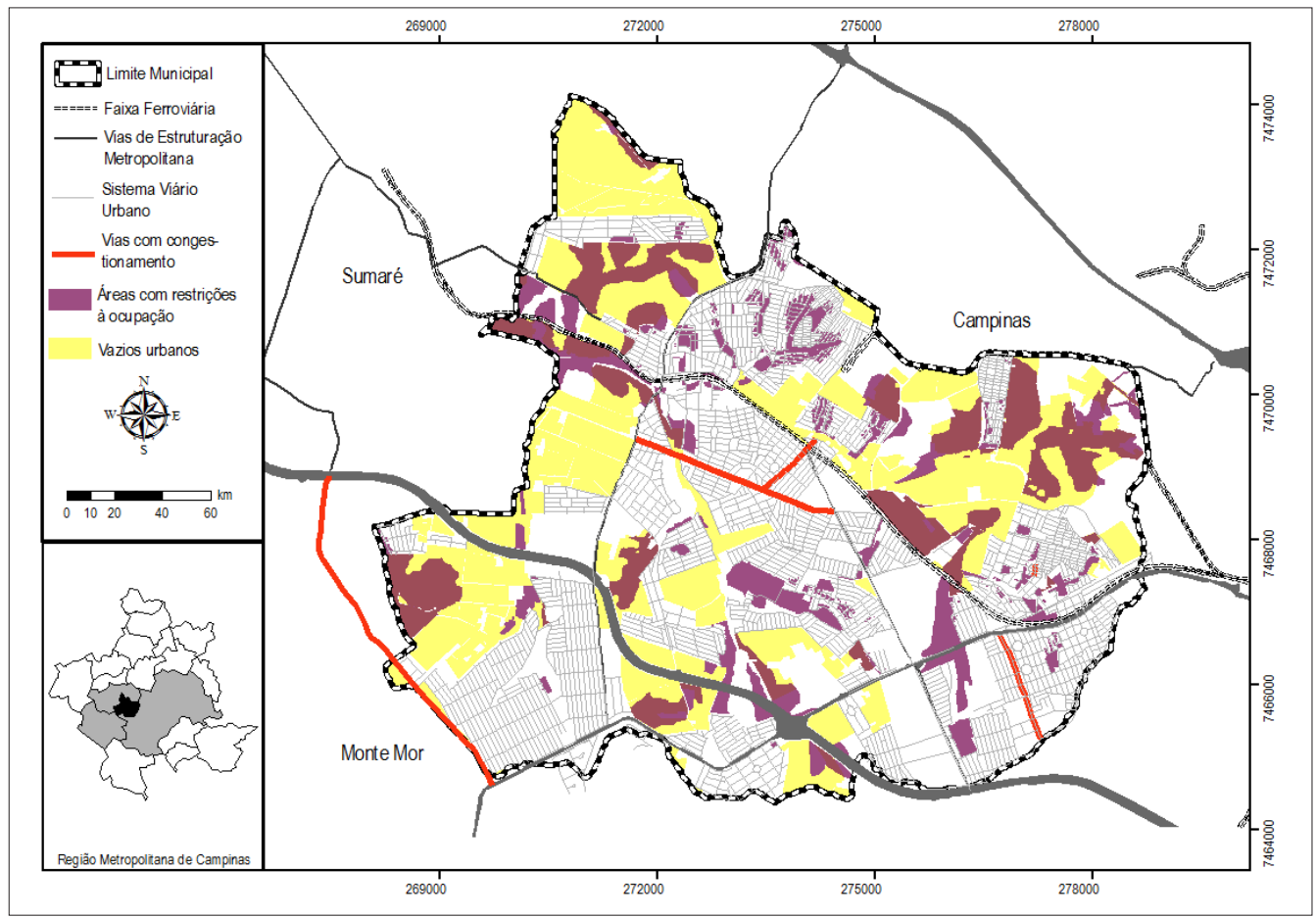

Organização: Autor (2012).

A reduzida área territorial é agravada na delimitação de regiões possíveis de ocupação devido à existência de eixos viários importantes para o estado de São Paulo como rodovia dos Bandeirantes (SP-348) e a rodovia Jornalista Franscisco Aguirro Proença (SP101) que limitam a urbanização. Além destes, a Rodovia Anhanguera (SP-330) e a Rodovia Dom Pedro I passam nas proximidades do município. Parte da malha ferroviária da FEPASA - Ferrovia Paulista S.A. também está localizada em Hortolândia.

Da área ocupada e/ou disponível para urbanização, parte relevante possui restrições de adensamento. Além disso, o fluxo entre os bairros pelo sistema viário intraurbano é comprometido devido à dificuldade de cruzar as rodovias, tanto por automóvel como por bicicletas e a pé, isolando determinados bairros do município. Assim, áreas de conurbação consolidada (próximas de Monte Mór e Campinas) acabam utilizando comércios e serviços públicos dos municípios vizinhos, constituindo-se como verdadeiras ilhas dentro do perímetro urbano.

As indústrias de alta tecnologia da informática, alimentícia e farmacêutica instaladas em Hortolândia, sobretudo a partir dos anos de 1980 pela guerra fiscal e afrouxamento das legislações, provocou alguns impactos no município. Estes vão desde a atração de loteamentos irregulares e regulares no seu entorno que levou à conurbação de determinadas regiões (como nas proximidades de Sumaré e Campinas) facilitados pela localização de excelentes eixos viários que conectam a região até a capital e o litoral paulista. Uma vez que a instalação dessas indústrias data antes do Estatuto da Cidade, instrumentos como o Estudo de Impacto de Vizinhança são inexistentes e a flexibilização de algumas legislações, já vigentes na época, acirrou o dilema. 
Essa estrutura espacial, no espaço intraurbano, levou ao isolamento de alguns bairros entre as rodovias, impedindo a instalação de meios alternativos de transporte. A conurbação, por outro lado, gera, conforme discutido em trabalhos anteriores (POLIDORO, 2012; POLIDORO, 2011; POLIDORO et. al., 2010), a dificuldade de aplicação de instrumentos de planejamento urbano como as leis de zoneamento, parcelamento do solo e loteamentos, código de obras e posturas, diretrizes do sistema viário e outros, já que os problemas não remetem apenas a uma única municipalidade.

A falta de infraestrutura nas áreas mais periféricas (como nas localizadas sobre as áreas de conurbação com Campinas) também é um dos problemas da aglomeração e gera dificuldades na gestão fiscal, cobrança das taxas e planejamento de instalação dos equipamentos públicos como escolas e postos de saúde. Este fator agrava-se em escala regional, já que os munícipes que vivem sobre os limites político-administrativos vão, eventualmente, utilizar os serviços públicos do município vizinho. Do ponto de vista comercial e de serviços, ocorre uma concentração de receita nos limítrofes, em detrimento de Hortolândia.

A partir do contexto anterior, duas propostas inovadoras foram discutidas na revisão do Plano Diretor de Hortolândia. A primeira remete à adequação das indústrias na nova demanda social do município: acesso legal à terra urbana, infraestrutura e projetos ambientais. Partindo do pressuposto da dívida socioambiental desses empreendimentos com a população, uma matriz de impacto de vizinhança na pós-ocupação foi desenvolvida, de acordo com a necessidade de mensurar as implicações existentes desses empreendimentos no município. As ressalvas, entretanto:

Não se sugere aqui encarar os agentes econômicos presentes em Hortolândia enquanto inimigos do município, pelo contrário. Propõe-se, reafirmar a parceria com os responsáveis pelo pleno desenvolvimento econômico da municipalidade de modo a inserir, dentro dos privilégios alcançados na cidade, a população hortolandense. (REVISÃO DO PLANO DIRETOR MUNICIPAL DE HORTOLÂNDIA, ETAPA III, s/p. 2011)

A construção da matriz foi baseada em Lollo (2006), Leopold (1971), Smardon (1976), Dee (1972) e desenvolvida por Polidoro (2012). Em relação à delimitação da área de abrangência, sugere-se utilizar o conflito no sistema viário de modo a estabelecer os limites direto do impacto. Para facilitar a coleta de dados, sistematização e análise, a marcação das áreas pode ser feita, além de respeitando os limites mencionados, os setores censitários do IBGE, que é atualmente a única fonte de dados agregados em microescala.

A matriz proposta considera nove características do impacto identificado ou avaliado como: existência ou não do impacto; duração (curto ou longo prazo); reversibilidade (reversível ou irreversível); magnitude (pequeno, moderado, maior); relação espacial (direto, indireto, sinérgico); importância (1 a 10, sendo baixo o menor valor e alto o maior valor); impacto ambiental (obedecendo 0 a 1 sendo o primeiro pouca qualidade e 1 boa qualidade); o custo/benefício e a significância. No quadro seguinte, é possível vislumbrar a legenda para preencher a matriz, o tipo de escala e o determinador. 
Quadro 1 - Legenda para preenchimento da Matriz de Impactos da Pós-Ocupação

\begin{tabular}{|c|c|c|c|}
\hline $\begin{array}{l}\text { Característica do impacto } \\
\text { identificado ou avaliado }\end{array}$ & $\begin{array}{c}\text { Descrição ou medida } \\
\text { de avaliação }\end{array}$ & $\begin{array}{l}\text { Tipo da } \\
\text { escala }\end{array}$ & Determinado por \\
\hline Existência & sim ou não & nominal & Julgamento de especialistas \\
\hline Duração & curto ou longo prazo & nominal & Julgamento de especialistas \\
\hline Reversibilidade & $\begin{array}{l}\text { reversível ou } \\
\text { irreversível }\end{array}$ & nominal & Julgamento de especialistas \\
\hline \multirow[b]{2}{*}{ Magnitude } & $\begin{array}{l}\text { pequeno, moderado, } \\
\text { maior }\end{array}$ & ordinal & Julgamento de especialistas \\
\hline & $\begin{array}{l}1 \text { a } 10, \text { com } 1 \\
\text { representando pequeno; } \\
5 \text { moderado e } 10 \text { grande }\end{array}$ & intervalo & Julgamento de especialistas \\
\hline Relação espacial & $\begin{array}{l}\text { direto, indireto ou } \\
\text { sinérgico }\end{array}$ & nominal & Julgamento de especialistas \\
\hline Importância & $\begin{array}{l}1 \text { a } 10, \text { com } 1 \\
\text { representando Baixo e } \\
10 \text { representando Alto }\end{array}$ & intervalo & Julgamento subjetivo \\
\hline Impacto Ambiental & $\begin{array}{c}0 \text { a } 1, \text { com } 1 \\
\text { representando } \\
\text { Pouca Qualidade e } \\
1 \text { representando Boa } \\
\text { Qualidade }\end{array}$ & intervalo & $\begin{array}{l}\text { Julgamento subjetivo ou por } \\
\text { especialistas }\end{array}$ \\
\hline Custo/Benefício & $\begin{array}{c}(+) \text { para benefício e }(-) \\
\text { para custo }\end{array}$ & nominal & Julgamento subjetivo \\
\hline Significância & $\begin{array}{l}\text { Sem impacto; impacto } \\
\text { insignificante; impacto } \\
\text { significante; impacto } \\
\text { mitigável; impacto } \\
\text { desconhecido }\end{array}$ & nominal & $\begin{array}{l}\text { Subjetivo e julgamento por } \\
\text { especialistas }\end{array}$ \\
\hline
\end{tabular}

Fonte: Polidoro (2012)

Considerando que é uma matriz de pós-ocupação, sugere-se fortemente que ela seja analisada em períodos históricos, sobretudo em duas ocasiões (por exemplo, utilizando dados do IBGE para 2000 e 2010). Entretanto, a inexistência dos dados setoriais não exclui a necessidade do estudo que deve adaptar-se à realidade do local e promover levantamentos e construção de cenários, quando necessários.

Os aspectos físicos e bióticos incluem, segundo Polidoro (2012), a avaliação da situação da água superficial/sistema hidrológico e das águas subterrâneas. Considerando a dificuldade em se obter tais dados de forma temporal, indica-se o uso de estudos das 
agências ambientais locais. A qualidade do ar pode ser medida tanto pela emissão de gases e partículas do empreendimento como pelo aumento do tráfego, segundo tipo do automóvel, na área de abrangência. Também inclusos nessa categoria, o solo, geologia, fauna e flora e a paisagem, onde às vezes, a instalação de obras de porte considerável é responsável por dizimar o panorama local, como o skyline.

Os aspectos urbanísticos englobam, de acordo com Polidoro (2012), o adensamento das vias de acesso (automóveis que acessam a área devido ao empreendimento); transporte público (número de pessoas que o utilizam para acesso); estacionamento (atendimento à demanda); polos geradores de tráfego e ruído; faixas de ciclovia (disponibilidade para transporte alternativo); valorização imobiliária (aumento ou redução dos impostos na região); adensamento populacional; mudanças de zoneamento (passíveis de análise por meio de alterações na legislação); áreas de lazer/espaços abertos.

Aspectos de infraestrutura devem indicar o tocante à estação de tratamento e rede de esgoto, rede de água e drenagem pluvial, rede elétrica, telefonia, iluminação pública e pavimentação. Este item é um dos mais importantes, sobretudo para o poder público que na maioria das vezes é responsável pela instalação da infraestrutura necessária para o funcionamento de alguns empreendimentos e quando estes atraem novos usos no entorno, na ampliação dos serviços.

Uma vez construída a matriz para cada empreendimento acordado com a prefeitura, será possível firmar parcerias entre o poder público e privado almejando a minimização dos impactos encontrados e distribuindo o ônus entre os agentes envolvidos no processo de construção da cidade. A matriz pode ser observada no Anexo 1.

$\mathrm{Na}$ segunda proposta, o zoneamento urbano (apresentado na figura 4), tentou-se adotar uma proposta mais flexível, levando em consideração a estrutura atual do sistema viário e possibilidades de alterações, os aspectos ambientais, a densidade demográfica e a disponibilidade de infraestrutura. A existência dos grandes eixos viários na área urbana que provocam poluição sonora e do ar, além de prejudicar a caminhabilidade da população foi considerada, junto com seu entorno, enquanto uma faixa de preservação ambiental a ser executados projetos de arborização específicos. As cinco zonas criadas são:

- CPUA - Corredor de Proteção Urbano Ambiental - Esta zona se refere ao resultado das discussões oriundas da Fase II em que foram explicitados os dilemas da conurbação e da existência dos anéis viários e ferroviário dentro do espaço urbano de Hortolândia. Assim, o Corredor de Proteção Urbano Ambiental visa à construção de planos e projetos, nas áreas demarcadas, visando à arborização de modo a constituir uma "barreira ecológica" para minimizar impactos sonoros e de ar. Esta área pode ser usada, ao mesmo tempo, para fins de esporte e lazer como a criação de faixas para pedestres.

- ZPAL - Zona de Preservação Ambiental e Lazer - A ZPAL agrega as áreas de preservação permanente (APP) presentes em Hortolândia, conservadas ou não, que, de acordo com a Lei Federal 4.771, devem ser mantidas intactas e sem ocupações nas faixas de margem. Devido à inexistência e/ou reduzida quantidade de terrenos públicos disponíveis para a instalação de equipamentos urbanos, propõe-se atribuir a esta zona a função múltipla de preservação ambiental e lazer. 
- ZAIS - Zona Ambiental de Interesse Social - agrega os Assentamentos Precários existentes em Hortolândia que, de acordo com o Plano Diretor Ambiental, também se localizam em áreas não indicadas para a ocupação, seja por estarem em APPs ou por alguma razão e limitação física são improprias para manterem-se, representando riscos. É determinada como uma zona ambiental e ao mesmo tempo de interesse social, pois visa articular os dois aspectos que, nesta zona, são carentes de políticas públicas e merecem prioridade das ações do gestor municipal.

- ZMOC - Zona Mista de Ocupação Controlada - agrega locais cuja ocupação pode acarretar problemas ambientais devido à aptidão do meio físico ou ainda dos equipamentos urbanos e comunitários que podem encontrar-se saturados.

- ZMOP - Zona Mista de Ocupação Prioritária - são os locais identificados com aptidão física e ambiental favorável à ocupação. Nesta mesma região, encontram-se vastos vazios urbanos que podem sofrer novas indicações de legislação urbanística quando ocorrer seu parcelamento, auxiliando numa nova configuração do sistema viário e verticalização de edifícios. Esta zona é determinada como Mista, pois visa indicar a construção de moradias, preferencialmente, de interesse social e usos que incentivem a geração de trabalho e comércio local. Deve-se executar a instalação de completa infraestrutura antes da execução dos projetos possíveis supracitados.

- ZROC - Zona Residencial de Ocupação Controlada - refere-se às regiões com ocupações predominantemente residenciais e consolidadas que, devido a limitantes ambientais e/ou de saturação de equipamentos públicos e/ou falta de infraestrutura, devem permanecer com uso estritamente residencial e de ocupação controlada.

- ZR - Zonas Residenciais - são localidades com predominância do uso residencial e localizadas próximas a zonas ou usos predominantemente conflitantes - como o industrial. Podem ainda estar próximas de entroncamentos viários com tráfego intenso, dificultando o deslocamento da população. Apesar de não possuírem necessariamente impedimentos ambientais para o adensamento, recomenda-se o controle de ocupação destas áreas devido aos usos conflitantes nas áreas vizinhas.

- ZCS - Zona de Comércio e Serviços - está localizada em áreas onde este uso já é predominante e em vastos vazios urbanos que podem agregar, devido ao fácil deslocamento por meio das vias estruturantes e anéis viários, da população para atividades comerciais e de serviços. Os usos permissivos desta zona são aqueles impeditivos nas zonas mistas, e esta ZCS está espacialmente distribuída no território de forma estratégica para atender toda a população, sobretudo a localizada em áreas de conurbação e periferias.

- ZEII - Zona Especial de Interesse Institucional - agrega as áreas como a Estação de Tratamento de Esgoto e o Presídio de Hortolândia. São áreas que podem interessar ao poder público.

- ZTI - Zona Técnica e Industrial - é caracterizada por regiões com uso predominantemente industrial. Cabe, nesta zona, apoiar a manutenção e 
fortalecimento das indústrias de Hortolândia visando ainda atrair o uso "técnico", ou seja, empreendimentos que, não industriais, possam servir de atividade complementar àqueles já instalados.

- ZETI - Zona de Expansão Técnica e Industrial - abriga vazios urbanos e áreas potenciais para receber novos empreendimentos técnicos e industriais. Dar-se-á preferência àqueles de baixo impacto, compatíveis com a reduzida malha urbana de Hortolândia. Os novos empreendimentos devem obrigatoriamente se submeter aos estudos EIA/RIMA e EIV, abrangendo também abordagens geológico-geotécnicas.

Figura 4 - Proposta do zoneamento urbano de Hortolândia - SP

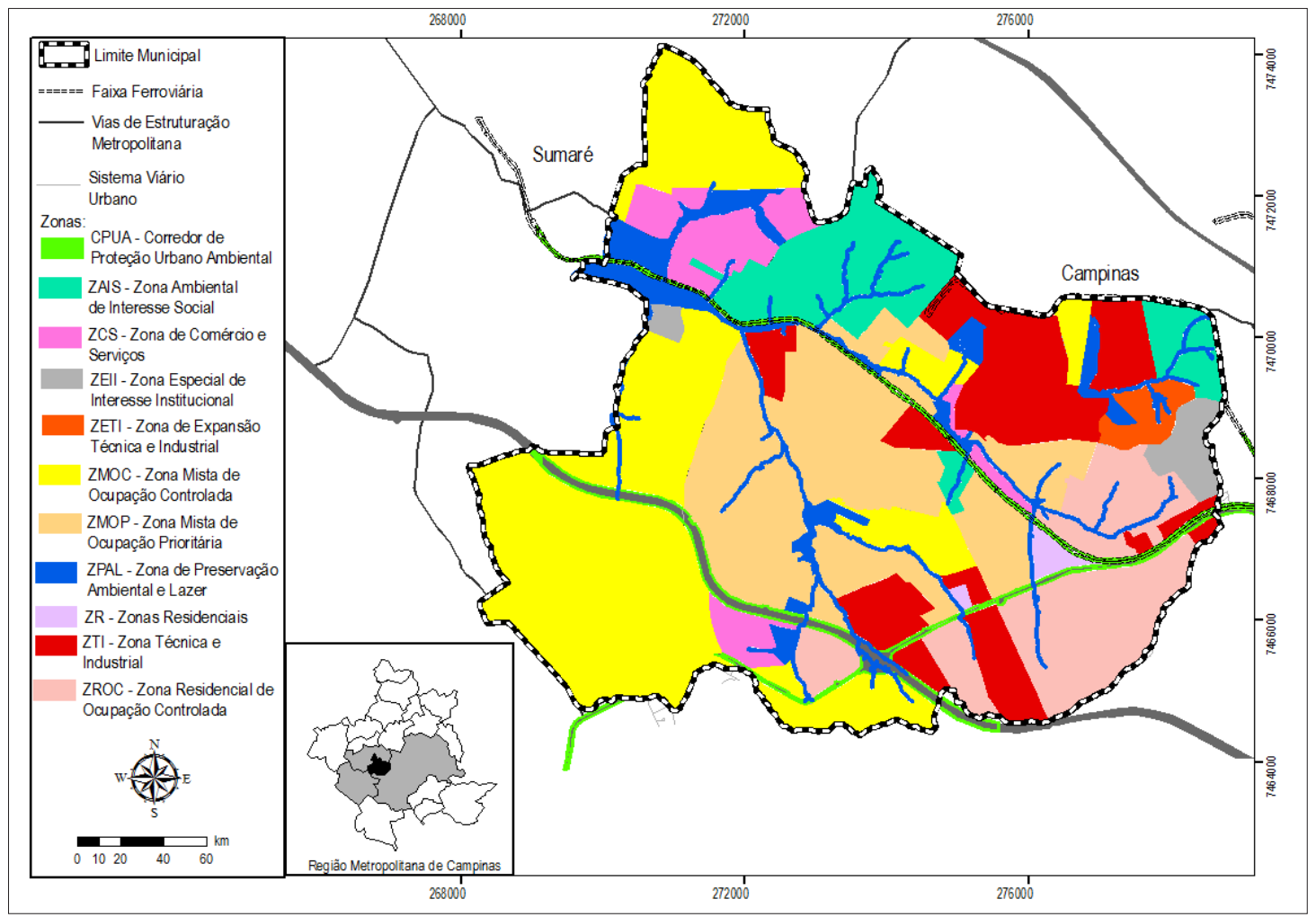

Organização: Autor (2012)

\section{À GUISA DE CONCLUSÃO: DESAFIOS TÉCNICOS E INSTITUCIONAIS DA IMPLANTAÇÃO DAS PROPOSTAS}

Outros autores já discorreram sobre os desafios e as ilusões dos planos diretores (mais notavelmente Villaça, 2005). Também tivemos oportunidade de tratar do assunto em outra ocasião (POLIDORO, 2012) sobre os trabalhos desenvolvidos nos estados de São Paulo e Paraná.

Enquanto em São Paulo existe a predominância da relativa liberdade dos municípios em desenvolverem e avaliarem seus planos diretores, no estado do Paraná, o órgão estadual (Paranacidade) vinculado à Secretaria de Desenvolvimento Urbano, é quem 
determina todo um metodismo aos planos diretores. Os municípios que utilizam verba deste órgão para elaboração dos trabalhos ou lhe requisitam a supervisão passam pelas etapas impostas pelo Paranacidade. Em ambos os estados, a obrigação constitucional da elaboração destes trabalhos para a concessão de verbas é um dos principais motivos de elaboração.

O que se observou, sobretudo no estado do Paraná, é o boom da elaboração dos planos diretores ${ }^{2}$, sobretudo a partir de 2004. Municípios com número ínfimo de habitantes se viram obrigados a elaborar seus planos diretores ${ }^{3}$ na mesma sistemática que aqueles dez vezes maiores também o fizeram, desde que financiados pelo Paranacidade.

Apesar de nos propormos a discorrer sobre os desafios técnicos e institucionais que acabam por serem consequentemente políticos no município de Hortolândia, não seria mera coincidência os mesmos dilemas serem observados em outras municipalidades brasileiras.

Ressalta-se que os desafios - técnicos e institucionais - não são necessariamente desvinculados um ao outro e integram, na totalidade, resultado da deficiência de articulação política na elaboração das políticas urbanas.

Os principais desafios técnicos são relacionados ao processo pelo qual os planos diretores são elaborados. A contratação dos serviços por empresas terceirizadas via menor preço já configura, per si, um problema para gerar estudos de qualidade. Com exceção dos casos de parcerias entre prefeituras e universidades, discutidos por Braga (1995), a incapacidade técnica de desenvolvimento dos trabalhos concentra-se, inicialmente, nas consultorias.

Com uma tradição já conhecida de reprodução de planos diretores entre diferentes municípios, os serviços terceirizados, muitas vezes precários, acabam sendo aprovados nas prefeituras pela também falta de técnicos preparados para o trabalho.

No caso de Hortolândia, além da despreparação técnica para avaliação dos estudos propostos, a composição da equipe técnica de avaliação representava, na sua totalidade, pessoal contratado por cargos políticos. Assim, os anseios da coletividade ficam em jogo diante dos conflitos de interesse.

Mesmo quando existe o conhecimento técnico de avaliação destes planos diretores, o problema esbarra nas prioridades dos gestores que, diversas vezes, representam grupos locais com interesses particulares. Não é à toa que a fase mais aguardada e que possui as discussões mais calorosas é aquela que propõe o zoneamento e o perímetro urbano municipal.

A inexistência de dados e bases cartográficas em escalas compatíveis para a geração de propostas pertinentes não são barreiras para a aprovação de normas e leis urbanísticas e ambientais. O zoneamento do interesse de pequenos grupos, travestidos de poder público, predomina no processo de aprovação. Isto é facilitado nas eventuais relações promíscuas entre poderes executivo e legislativo.

2 Apenas 10 dos 399 municípios do estado do Paraná não haviam iniciado a elaboração dos seus planos diretores em 2010, segundo o SEDU-Paranacidade.

3 Municípios com menos de 20.000 habitantes no estado do Paraná foram induzidos a elaborar seus planos diretores como requisito para obtenção de verbas do Governo do Estado, conforme Decreto Estadual 2.581/2004 (ESTADO DO PARANÁ, 2004). 
Estes desafios técnicos que configuram, concomitantemente, desafios institucionais, carecem de maior monitoramento. Este monitoramento deve coexistir via legislação federal na legitimação da soberania popular em todo o processo de construção e aprovação dos planos, restringindo a participação de servidores não públicos, bem como da própria população por meio de ampla divulgação dos resultados e discussões dos planos - muitas vezes indisponíveis na internet.

Outrossim, é necessário vencer o sistema arcaico ainda predominante no poder público, na escala local. Apesar da relativa modernização da infraestrutura de algumas prefeituras, as relações de clientelismo ainda persistem e prejudicam o delineamento de políticas urbanas inclusivas e participativas.

A aproximação da universidade e do poder público, na escala local, se mostra necessária. As parcerias entre estas instituições devem ser encorajadas para que planos diretores inovadores sejam desenvolvidos e façam jus às reais necessidades dos municípios, necessidades estas muitas vezes não preconizadas nas legislações federais. Por outro lado, intermediar a articulação política aos ensejos operacionais na execução dessas propostas e vencer a tendência tecnocrata é um velho desafio para o qual parte considerável dos técnicos não estão preparados.

\section{REFERÊNCIAS}

BRAGA, R. Plano Diretor Municipal: três questões para discussão. Caderno do Departamento de Planejamento, Presidente Prudente, v. 1, n. 1, p. 15-20, 1995.

CÔRREA, R. L. Sobre agentes sociais, escala e produção do espaço: um texto para discussão. A Produção do Espaço Urbano. Ana Fani Alessandri Carlos, Marcelo Lopes de Souza, Maria Encarnação Beltrão Spósito (orgs.). Editora Contexto, 2011.

DAMIANI, A. L. Cidades médias e pequenas no processo de globalização. Apontamentos bibliográficos. América Latina: cidade, campo e turismo. Amalia Inés Geraiges de Lemos, Mónica Arroyo, María Laura Silveira (orgs.). CLACSO, Consejo Latinoamericano de Ciencias Sociales, San Pablo, 2006.

DEE, N., J. BAKER, N. DROBNY, K. DUKE, WHITMAN, T., FAHRINGER, P. An Environmental Evaluation System for Water Resource Planning. Water Resource Research, v. 9, pp. 523-535, 1972.

ESTADO DO PARANÁ. Decreto 2.581 de 17 de fevereiro de 2004. Disponível em: <http://celepar7cta. pr.gov.br/SEEG/sumulas.nsf/2b08298abff0cc7c83257501006766d4/32842cf5abd8efac03256e9900623486? OpenDocument>. Acesso em: 10 nov. 2011.

INSTITUTO BRASILEIRO DE GEOGRAFIA E ESTATÍSTICA. Dados de movimentos pendulares do Censo 2000. Disponível em: <http://www.ibge.gov.br/censo/>. Acesso em: 2 mar. 2012.

INSTITUTO BRASILEIRO DE GEOGRAFIA E ESTATÍSTICA. Dados demográficos do Censo 2010. Disponível em: <http://www.ibge.gov.br/cidadesat/topwindow.htm?1>. Acesso em: 1 mar. 2012.

INSTITUTO DE PESQUISA ECONÔMICA APLICADA. População e PIB das cidades médias crescem mais que no resto do Brasil. Release IPEA. 17 de julho de 2008. Disponível em: <http:/ / www.ipea.gov.br/ sites/000/2/pdf_release/32_release_PIBdascidades.pdf>. Acesso em: 29 fev. 2012.

LENCIONI, S. A metamorfose de São Paulo: o anúncio de um novo mundo de aglomerações difusas. Revista Paranaense de Desenvolvimento. IPARDES. N. 120, 2011.

LEOPOLD, L.B., CLARKE, F.E., MANSHAW, B.B., BALSLEY, J.R. A Procedure for Evaluating Environmental Impacts. U.S. Geological Survey Circular n. 645, Government Printing Office, Washington, D.C. 1971. 
LOLLO, J. A.; RÖHM, S. A. Proposta de matriz para levantamento e avaliação de impactos de vizinhança. Holos Environment, Rio Claro - SP, v. 5, n. 2, p. 169-183, 2006.

PEREIRA, R. H. M. Uma proposta de tipologia para a mobilidade pendular. Anais do V Encontro Nacional sobre Migração. Campinas. UNICAMP, 2007.

PEREIRA, R. H. M.; HERRERO, V. Mobilidade pendular: uma proposta teórico-metodológica. Textos para discussão do IPEA. 2009.

POLIDORO, M. Conurbação e dispersão em glomeração urbana: desafios ao planejamento. Dissertação de Mestrado em Engenharia Urbana. Universidade Federal de São Carlos. São Carlos - SP. 205f. 2012.

POLIDORO, M.; BARROS, M. V. F.; LOLLO, J. A.; MARCHETTI, M. C. Análise multitemporal da evolução da mancha urbana no entorno da BR-369 dos municípios paranaenses. XVI Encontro Nacional dos Geógrafos, 2010, Porto Alegre. Anais do XVI Encontro Nacional dos Geógrafos. Porto Alegre: Associação dos Geógrafos Brasileiros, 2010, v. 1, p. 1-9.

REVISÃO DO PLANO DIRETOR MUNICIPAL DE HORTOLÂNDIA. Etapa III - Viabilização do PDP Propostas, Estratégias e Instrumentos. CD, 2011.

SANTOS, M. A urbanização brasileira. São Paulo. Editora Hucitec. 1996.

SINGER, P. I. Economia Política da Urbanização. São Paulo: Brasiliense, 1973.

SMARDON, R.C., PEASE, J.R., DONHEFFNER, P. Environmental Assessment Form, Environmental Impact Assessment: A Framework or Local, 1976.

SOBREIRA, D. P.; CUNHA, J. M. P. A metrópole e seus deslocamentos populacionais cotidianos: o caso da mobilidade pendular na Região Metropolitana de Campinas. Encontro da Associação Nacional de Pesquisa e Pós-Graduação em Planejamento Urbano e Regional - ANPUR, 13, 2007, Belém. Anais... Belém: ANPUR, 2007.

SPÓSITO, M. E. B. A produção do espaço urbano: escalas, diferenças e desigualdades socioespaciais. A Produção do Espaço Urbano. Ana Fani Alessandri Carlos, Marcelo Lopes de Souza, Maria Encarnação Beltrão Spósito (organizadores). Editora Contexto, 2011.

VILLAÇA, F. J. M. As ilusões do plano diretor. São Paulo: Internet, 2005.

Recebido em 09/04/2012

Aceito em 02/07/2012 


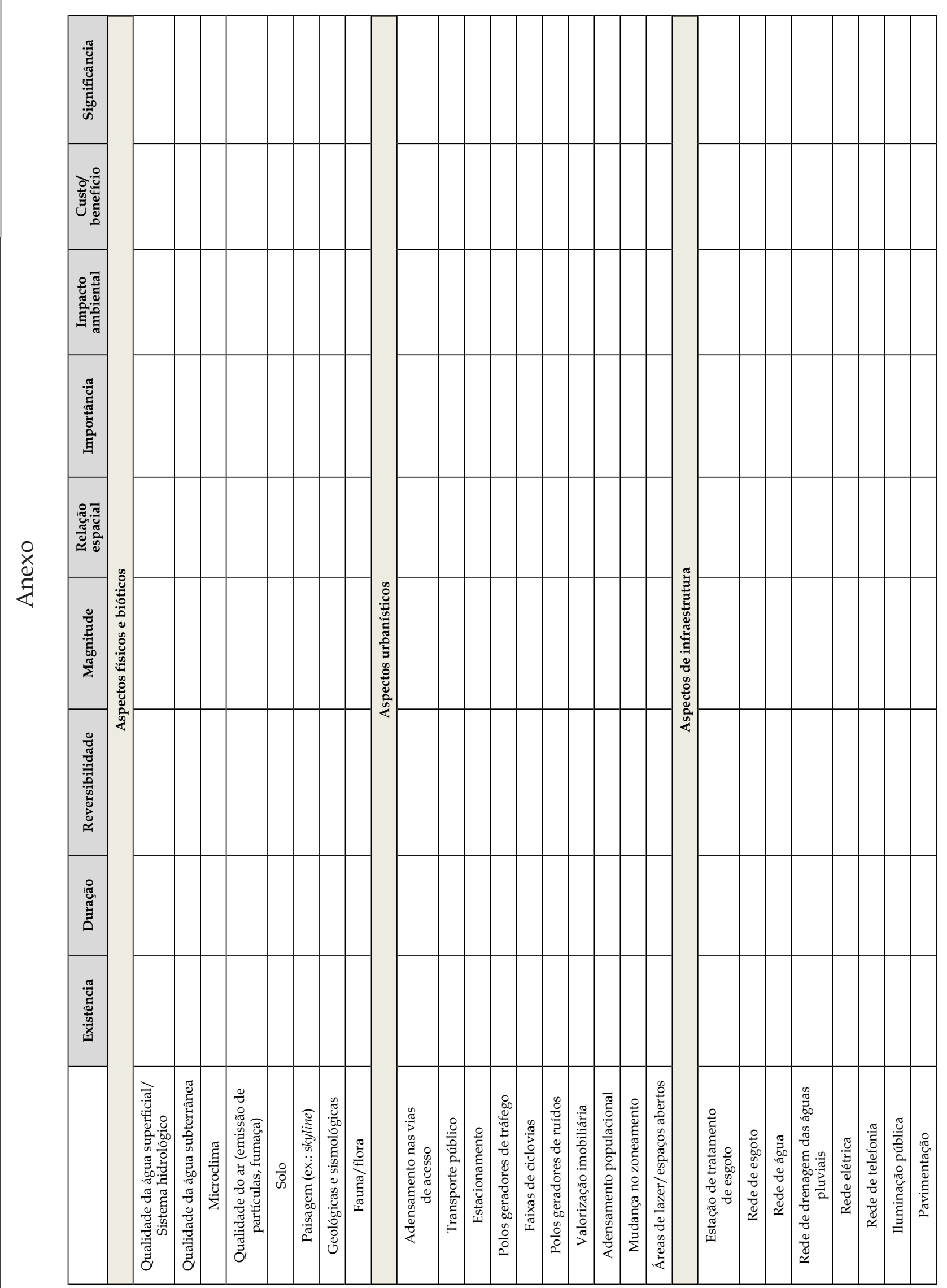

